\title{
Evolution of a class in fiber-optic communications
}

\author{
Joseph Palais
}

Joseph Palais, "Evolution of a class in fiber-optic communications," Proc. SPIE 9663, Eighth International Topical Meeting on Education and Training in Optics and Photonics, $96630 Z$ (6 October 2003); doi: 10.1117/12.2207481

SPIE Event: Eighth International Topical Meeting on Education and Training in Optics and Photonics, 2003, Tucson, Arizona, United States 


\title{
Evolution of a class in fiber-optic communications
}

\author{
Joseph Palais \\ Arizona State University \\ Department of Electrical Engineering \\ Ira A. Fulton School of Engineering \\ Tempe, Arizona 85287-5706
}

\begin{abstract}
:
Classes in fiber-optic communications, presented at Arizona State University (ASU) for four decades, have evolved in both content and delivery. Content updates followed the development of new components and network strategies, while delivery methods changed from blackboard-to- television-to-Internet. Evolution, evaluation, and future direction of these classes are described.
\end{abstract}

\section{Introduction}

A two-semester sequence in fiber optic communications has been offered at Arizona State University by the author since 1979. The first course has been offered almost every fall semester since then and the advanced course has been offered many times as a spring course. The first course is taught at the senior/first-year-graduate level and the second course at the first-year-graduate level. There is a laboratory for undergraduate students for the first course. The courses generally follow a textbook written by the present author and first published in 1984. ${ }^{1}$ The course content, the textbook, and delivery procedures have evolved over the past 24 years.

It is not surprising that course materials in technical subjects change. Fiber optics is a good example of this. At the time of the first presentation of the course in 1979, fiber communications was in its infancy. Since then advancements have appeared at a rapid pace. Numerous improvements and application evolved over the years. The fundamentals did not vary from what was known in the 1970s, but new components, new network strategies, and new applications became available every year necessitating changes in the course content and in the textbook. Unrelated to course content and textbook upgrades was a series of changes in the course delivery format.

The course content, textbook, and delivery evolution described for the fiber course parallels that of many other university science classes developed and presented over the last 25 years.

\section{Course Content}

Table 1 indicates some of the changes that have occurred since the first low-loss fiber was developed in 1970. The first column in the table describes the property of interest and the following four columns describe the change with time in that property. As an example, some of the first systems operated with carrier wavelengths near $820 \mathrm{~nm}$, used multimode fibers having losses of $3 \mathrm{~dB} / \mathrm{km}$, ran at a rate of $45 \mathrm{Mb} / \mathrm{s}$ over $10 \mathrm{~km}$ 
paths, and used time-division multiplexing. Skipping to the present decade, we have systems operating in the long-wavelength region (1260-1675 nm) with fiber losses of 0.2 $\mathrm{dB} / \mathrm{km}$ and running at rates of $40 \mathrm{~Gb} / \mathrm{s}$. The fibers are single-mode, non-zero dispersion shifted fibers to improve bandwidth. The systems are dense-wavelength-division multiplexing allowing for numerous $40 \mathrm{~Gb} / \mathrm{s}$ channels along a single fiber. With amplifiers (EDFAs or Raman), the system lengths are as long as needed over terrestrial and oceanic paths.

Advances in fiber technology produced systems capable of transmitting at ever increasing rates and longer distances. In addition, price reductions and component simplifications made fiber optics a candidate for lower-cost, low-rate, short-distance applications (such as LANs) as well.

Table 1 indicates fiber improvements over time. Most of the earlier components and systems remain viable. The newer developments have just added to fiber capabilities.

The lectures were easily updated on a yearly basis by incorporating new material as it became available. New developments could be mentioned in class almost as soon as they were announced in journals or at conferences. However the fundamentals of propagation in fibers, light generation (chiefly laser diodes and light-emitting diodes), and photodetection (PIN and avalanche photodiodes) did not change substantially. These fundamentals have always been the core of the course.

\section{Course Textbook}

The course followed the authors textbook ${ }^{1}$ fairly closely. The textbook was first published in 1984. Before it became available, the course was taught from notes that later became part of the textbook. The problem with textbooks in technical areas is the speed with which they become outdated. It the case of fiber-optic communications it is not a case of material becoming obsolete. It is more a case of new material becoming available. The new subjects were added in a second edition in 1988, a third edition in 1992, and a fourth edition in 1998. A fifth edition is in preparation. Even with this fairly aggressive publishing schedule, the book remains slightly behind the technology.

The textbook has always contained a bibliography of useful fiber books. The number of books in the bibliography, tabulated in Table 2, reflect the growing interest in optical communications over the period covered.

Another change has been the retail cost of the course textbook. It was first published (1984) as a paperback and sold for \$14. The fourth edition (1998), in hardback, was recently priced at $\$ 80$. Translations have been published in Japanese, Korean, and Persian. A separately published international version in English has accompanied each new US edition.

\section{Course Delivery}

The course delivery format has undergone a number of significant changes. They are listed in Table 3 and are the major motivation for this paper. The first change, from a lecture hall with a blackboard to one with a whiteboard, was fairly modest but much appreciated. Although about twenty years have passed since I last used chalk, I can still feel the extreme drying of the skin produced by its contact with my fingers. 
The next change was more significant. Television studios were constructed and a network was assembled for delivering graduate-level classes to local companies. At its peak, more than 25 companies had receiving facilities. They included several sites for Motorola, Honeywell, and Intel, and single sites for Boeing, Lockheed, Litton, Phillips, VLSI, AG Communications, and others in the greater Phoenix area. On-campus students attended the live lectures as they were being televised. Students at the remote sites could watch the live lectures at their company locations and call in questions over telephone lines. Videotapes of the lectures were place on file in the library. A number of students chose to view the videotapes rather than attend classes. Additionally, we observed that the remote students did not watch the television broadcasts as they were transmitted, but recorded the lectures and watched them at times of their own convenience.

Student response to the televised lectures was quite positive. No exhaustive assessment was done (it should have been done), but the regular instructor evaluations showed very strong acceptance of the televised lecture system. I believe the reason was the good quality of the transmission, its reliability, and the great convenience afforded to the remote student. Driving to school from the workplace, parking, walking to class, attending the lecture, and then reversing the process would have been much too time consuming.

Faculty participation in the television presentation was almost never a big issue. The instructor could give a lecture while writing on a chalkboard or on a paper pad or could lecture from prepared slides (and in the 1990s from PowerPoint ${ }^{\mathrm{R}}$ slides). Homework and exams were delivered by a university courier. Company-employed proctors at the sites monitored exams. There was no additional faculty compensation for presenting televised classes.

In the 1990s the fiber course began being offered through the National Technological University (NTU). Students from all over the country attended the fiber class. The televised class was delivered by Satellite to the NTU facilities. NTU distributed the video to its students. Basically, NTU students viewed videotapes of the class lectures. The NTU students were a few days to a week or so behind the live class because of delays in delivering the videotapes. NTU pays the instructor a nominal amount for each enrolled student. Student response was positive. Again, the quality of service and the convenience factor were probably the most important factors in student acceptance of the NTU remote delivery system.

The next variation to the course, begun in the 1990s, was the introduction of simulations to the lectures. This was made possible as there was a PC in the television studio and its screen could be recorded and televised. A number of computer simulations of fiber optic phenomena were prepared and integrated into the lectures. Examples simulations are on wave travel and ray propagation through a GRIN fiber. These simulations were the subject of a previous ETOP presentation. ${ }^{2}$ They are available for viewing at the authors web site. ${ }^{3}$ This addition to the class is listed as a PC enhancement in Table 3.

In the late 1990s the Internet was becoming pervasive. All students had Internet access either in their own homes or at campus computing sites. Because of this, course materials were made available exclusively on the Web. Blackboard ${ }^{\mathrm{R}}$ (a popular commercial e-learning tool used to manage Web courses) was used. Materials posted included the lecture schedule, exam schedule, homework assignments, course 
announcements, grading policy, posted student grades, laboratory schedule, laboratory manual, simulations, links to relevant Internet sites (e.g., fiber companies), and teaching assistant and instructor access information. The Web site was used by all course participants: on-campus students, local-television students, and NTU students. This use of the Internet is sometimes referred to as an Internet enhanced course.

It was decided to offer the first fiber course entirely over the Internet for the Fall 2000 semester. One of the motivations was the ASU participation in the Arizona TriUniversity Master of Engineering program. This program combines courses taken at Northern Arizona University, the University of Arizona, and ASU. Classes taught over the Internet make them more accessible to students in the program than on-campus classes. Rather than an Internet-enhanced course, we are now talking about a true Internet course available in its entirety over the Internet.

Again, Blackboard ${ }^{R}$ was used for the course shell. It was decided to pre-record the lectures using a system call Tegrity WebLearner ${ }^{\mathrm{R}}$. At the time of the recording (summer 2000), we had no way of posting lectures presented in the TV studios directly onto the Web. Pre-recording has a number of advantages and disadvantages. One advantage is that lectures can be generic, without reference to the date given. Live lectures usually give cues as to when the lectures occurred. For example, the instructor may state that a homework set is due the next session. Without these cues, pre-recorded lectures can be used again other semesters. In fact, the pre-recorded lectures were used for a total of three successive Fall presentations of the first fiber class. Pre-recording frees the instructor from preparing and presenting live lectures. The disadvantage is that it is difficult to modify the class to add the latest changes in the technology. At the time of the digital recordings for the Internet, the course was simultaneously videotaped. All students had the option of watching the recorded videotapes in the TV studio at the assigned class time, watching the video tapes at a time of their choosing by checking them out from the library, or watching the lectures on the Internet. The videotaped lectures were transmitted for the local television and NTU students.

Tests were done in class for on-campus students. Exams for remote students were monitored by proctors.

Later, NTU gave its students the option of watching the lectures over videotapes or over the Internet. For these students the Internet removed the time-delay experienced in waiting for delivery of videotapes.

An extensive assessment of Internet delivery of the first course was made. The published results ${ }^{4}$ were generally favorable. A few on-campus students missed the direct contact with the lecturer. The convenience of being able to view the lectures at a place and time of their own choosing was the leading reason the students gave for approving the Internet format.

The second fiber course was also pre-recorded. This time RealPresenter was used for the recordings. The course was given on the Internet in Spring 2002.

In the latest incarnation of the first course (in Fall 2003) lectures are video streamed from the TV studios. On-campus students attend the live lectures. Online students can watch the lectures live on the Internet or can watch them at a later time. The lectures are typically archived and available on the Internet a few hours after the actual presentation. Students not enrolled for the Internet version of the course cannot view the lectures but can access all other material on the class Blackboard ${ }^{\mathrm{R}}$ web site. There is an extra fee for 
the Internet class. Video transmission and videotapes are no longer being provided. All distance learning is being done over the Internet. NTU has also migrated to Web-based classes. The faculty are compensated for the production and delivery of Internet classes.

Streaming video solves the problem of updating the class and the perceived problem of direct student-instructor contact for on-campus stydents. Assessment of this latest strategy will be performed at a later time.

\section{Discussion}

A lot has happened in the fiber communication industry since its inception in the 1970s. The fiber-optic communications courses at ASU have followed the progress of the technology. In addition, the course presentation has evolved as educational technology itself has progressed. Although fiber communications is now embedded in the world's communications structure, the field slowed considerably in the years 2002 and 2003. Employment is significantly down from earlier times. Industry layoffs have been extensive. A popular technical journal, Lightwave, reduced the number of printed pages from 210 in its October 2001 issue to 54 in its February 2003 issue. This is another indication of the decline in the fiber industry. It is not clear whether or not the robust nature of the field will return. The need to train large numbers of engineers in this area needs to be evaluated.

Internet courses may become universally accepted as being equivalent to, or better than, conventional face-to-face classes. In this occurs, then further refinements can be envisioned. Several possibilities come to mind.

One example would be to make the courses truly asynchronous. That is, make the course independent of the familiar semester system. With pre-recorded lectures, a student could start the course at any time. The course could be refreshed each time it was taught live.

As another example, it is possible for schools to sell its recorded courses as complete packages to other schools that might be interested in offering them to their own students. This might, or might not, be acceptable practice but it is technologically feasible.

Recorded courses can also be repurposed for use in short courses, non-degree courses, audit courses, and certificate courses.

All these possibilities are being considered for the fiber-optics communications course described in this paper.

\section{References}

1. J.C. Palais, Fiber Optic Communications, Prentice-Hall, $4^{\text {th }}$ ed., Upper Saddle River, NJ, 1998.

2. J.C. Palais, "Technology-Enhanced Fiber-Optic Education," Conference on Education and Training in Optics and Photonics (ETOP'99), Cancun, Mexico, July 1999. SPIE Conference Proceedings, SPIE Vol. 3831, pp. 252-258, June, 2000.

3. http://www.eas.asu.edu/ palais

4. S. Haag and J.C. Palais, "Engineering Online: Assessing Innovative Education," with Susan Haag, ASEE J. of Engineering Education, July 2002, pp. 285-290. 
Table 1. Course Content Timeline.

\begin{tabular}{|c|c|c|c|c|}
\hline & 1970s & $\longrightarrow$ & $\longrightarrow$ & $2000 \mathrm{~s}$ \\
\hline Wavelength & $820 \mathrm{~nm}$ & $1310 \mathrm{~nm}$ & $1550 \mathrm{~nm}$ & $1260-1675 \mathrm{~nm}$ \\
\hline Fiber loss & $3 \mathrm{~dB} / \mathrm{km}$ & $0.5 \mathrm{~dB} / \mathrm{km}$ & $0.2 \mathrm{~dB} / \mathrm{km}$ & \\
\hline Fiber type & Multimode & Single mode & DSF & NZ-DSP \\
\hline Light source & LED, LD & DFB LD & VCSEL & Raman lasers \\
\hline TDM data rate & $45 \mathrm{Mb} / \mathrm{s}$ & $2.5 \mathrm{~Gb} / \mathrm{s}$ & $10 \mathrm{~Gb} / \mathrm{s}$ & $40 \mathrm{~Gb} / \mathrm{s}$ \\
\hline Distance & $10 \mathrm{~km}$ & $100 \mathrm{~km}$ & & $10,000 \mathrm{~km}$ \\
\hline Optical amplifier & None & SOA & EDFA & Raman \\
\hline Modulation & Current & Electrooptic & & Electroabsorption \\
\hline Modulator & Internal & External & & \\
\hline Multiplexing & TDM & WDM & DWDM & OTDM \\
\hline Fiber data rate & $45 \mathrm{Mb} / \mathrm{s}$ & $25 \mathrm{~Gb} / \mathrm{s}$ & $1 \mathrm{~Tb} / \mathrm{s}$ & $5 \mathrm{~Tb} / \mathrm{s}$ \\
\hline Connectors & SMA & ST & $\mathrm{SC}$ & SFF \\
\hline Splices & Mechanical & Fusion & Quick splice & \\
\hline
\end{tabular}

Key: DSF, dispersion shifted fiber; NZ-DSF, non-zero dispersion shifted fiber; LED, light-emitting diode; LD, laser diode; DFB, distributed feedback; VCSEL, vertical-cavity surface-emitting laser; SOA, semiconductor optical amplifier; EDFA, erbium-doped fiber amplifier; TDM, time-division multiple xing; WDM, wavelength-division multiplexing, DWDM, dense wavelength-division multiplexing; OTDM, optical time-division multiplexing; SMA, ST, SC, different style connectors; SFF, small form factor.

Table 2. Number of Textbooks in Bibliography of Textbook.

\begin{tabular}{|l|l|l|l|l|l|}
\hline Year & 1984 & 1988 & 1992 & 1998 & 2004 \\
\hline Books & 40 & 70 & 109 & 178 & 210 \\
\hline
\end{tabular}

Table 3. Course Presentation Timeline.

\begin{tabular}{|c|l|}
\hline Time & Delivery \\
\hline 1979 & Chalkboard \\
\hline$\downarrow$ & Whiteboard \\
\hline$\downarrow$ & Local TV \\
\hline$\downarrow$ & National TV (NTU) \\
\hline$\downarrow$ & PC enhancements \\
\hline$\downarrow$ & Internet enhancements \\
\hline$\downarrow$ & Internet: Pre-recorded \\
\hline$\downarrow$ & Internet: NTU \\
\hline 2003 & Internet: Streaming video \\
\hline
\end{tabular}

